\title{
Búsqueda de afecciones genéticas como etiología de déficit intelectual en individuos que asisten a escuelas de educación especial
}

\author{
M Angélica Alliende ${ }^{1 a}$, Laura Cámpora ${ }^{2}$, Bianca C urotto $^{1 b}$ \\ Jessica Toro ${ }^{1 c}$, Alf Valiente ${ }^{1 c}$, Marcela Castillo ${ }^{1 \mathrm{~d}}$, \\ Fanny Cortés ${ }^{1}$, César Trigo $^{3 e}$, Cecilia Alvarado 4 , \\ Manuel Silva 4 , Margarita Caru5g. \\ Genetic screening to determine an \\ etiologic diagnosis in children with \\ mental retardation
}

Background: Mental retardation or intellectual disability affects $2 \%$ of the general population, but in $60 \%$ to $70 \%$ of cases the real cause of this retardation is not known. An early etiologic diagnosis of intellectual disability can lead to opportunities for improved educational interventions, reinforcing weak areas and providing a genetic counseling to the family. Aim: To search genetic diseases underlying intellectual disabilities of children attending a special education school. Material and methods: A clinical geneticist performed the history and physical examination in one hundred and three students aged between 5 and 24 years (51 males). A blood sample was obtained in 92 of them for a genetic screening that included a standard karyotype, fragile X molecular genetic testing, and search for inborn errors of metabolism by tandem mass spectrometry. Results: This approach yielded an etiological diagnosis in as much as 29 patients. Three percent of them had a fragile X syndrome. Inborn errors of metabolism were not detected. Conclusions: This type of screening should be done always in children with intellectual disability to establish an etiological diagnosis (Rev Méd Chile 2008; 136: 1542-51).

(Key words: Fragile X syndrome; Genetic screening; Mental retardation)

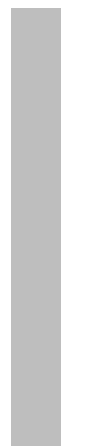

\footnotetext{
Recibido el 13 de diciembre, 2007. Aceptado el 19 de agosto, 2008.

Trabajo financiado por proyecto DI-U. de Chile: MULT 04/32-2.

${ }^{1}$ Unidad de Genética y Enfermedades Metabólicas, Instituto de Nutrición y Tecnología de los Alimentos (INTA), Universidad de Chile. ${ }^{2}$ Programa de Genética Humana, Universidad del Desarrollo. ${ }^{3}$ Escuela Especial Nuestro Mundo. ${ }^{4}$ Facultad de Ciencias Sociales, Universidad de Chile. ${ }^{5}$ Facultad de Ciencias, Universidad de Chile. Santiago de Chile.

aMagíster en Ciencias Biológicas c/m en Genética

bTecnólogo Médico

${ }^{\mathrm{c}}$ Bioquímico

dPsicólogo

e Magíster en Educación

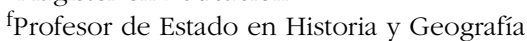

gDoctor en Ciencias
}

Correspondencia a: M. Angélica Alliende R. Unidad de Genética y Enfermedades Metabólicas, INTA, Universidad de Chile. Macul 5540, casilla 138, Santiago 11. Santiago de Chile. Fax: 56(2) 678-1489. E mail: malliend@inta.cl 
$\mathrm{L}$ a Asociación Americana para el Retardo Mental (RM) define esta condición como la discapacidad caracterizada por importantes limitaciones en el funcionamiento intelectual y la conducta adaptativa, que se expresa en destrezas conceptuales, sociales y de adecuación y que se presenta antes de los 18 años; con prevalencia de 2\% y 3\% y variaciones entre 1\% y 10\% según el tipo de población estudiada ${ }^{1-4}$.

El RM o déficit intelectual (DI) está determinado de manera importante por un coeficiente intelectual (CI) bajo; considerando $\mathrm{CI}=100$ como promedio normal, con límite inferior de normalidad en dos desviaciones estándar (DE) de este promedio (DE $=15)$. Cualquier CI menor a 70 corresponde a DI, distinguiéndose cuatro grados de severidad: DI leve, $\mathrm{CI}=55-69$, DI moderado $\mathrm{CI}=35-54$, DI severo CI $=20-34$ y DI profundo $<20^{2}$.

Identificar precozmente la etiología del DI en un niño, permite conocer el pronóstico y riesgo de recurrencia de la afección, establecer intervenciones terapéuticas y educativas, ayudar a la adaptación de la familia y lograr una mejor integración del individuo afectado a la sociedad; así como permitir a los padres acceder a mayor información y redes de apoyo ${ }^{5}$. Sin embargo la literatura actual informa que en DI moderado a severo sólo 65\% de los casos tienen etiología conocida y en DI leve la etiología puede ser establecida sólo en 20\% a 24\% de los $\operatorname{casos}^{6,7}$.

Considerando que los factores genéticos juegan un rol importante en el origen del DI, el diagnóstico etiológico es un desafío constante para el equipo de salud, especialmente por el gran número de afecciones potencialmente responsables de su etiología y por la disponibilidad creciente de exámenes diagnósticos, aplicando la tecnología de genética molecular y la información genética disponibles. Al conocer las alteraciones responsables del DI, es posible mejorar el manejo clínico de la enfermedad, mejorar la consejería genética de la familia y eventualmente prevenir, a través del asesoramiento genético, la recurrencia de afecciones discapacitantes en una familia ${ }^{8}$.

Las aberraciones cromosómicas constituyen la principal causa etiológica de DI (15\% a 40\% en los grados moderado a severo); sin embargo existe subutilización de los servicios de genética en el estudio de estos individuos y un porcentaje importante de ellos no ha sido examinado clínica- mente ni se ha sometido a exámenes considerados de rutina, como cariotipo y búsqueda de mutaciones características del síndrome Xq frágil ${ }^{9}$.

Las técnicas de citogenética molecular como la fluorescencia e hibridación in situ (FISH) y análisis comparativo del genoma en plataforma (array$\mathrm{CGH}$ ) permiten localizar secuencias específicas de ADN y detectar ganancias y pérdidas de ADN, respectivamente; constituyen el "cariotipo molecular" que con mayor resolución que el análisis cariotípico convencional, han aportado nuevas evidencias de la asociación del DI con anomalías cromosómicas $^{10,11}$. Así en estudios recientes de pacientes con DI de causa no precisada la utilización del cariotipo molecular ${ }^{12}$, ha permitido identificar aberraciones cromosómicas crípticas (pérdidas o ganancias menores a $3 \mathrm{Mb}$ ) en 16\% de individuos que tenían un cariotipo convencional normal ${ }^{13}$.

Por otra parte, el síndrome de Xq frágil (SXF) que se presenta en 1 de 4.000 hombres y en 1 de 8.000 mujeres ${ }^{14,15}$, aumenta a $2 \%-3 \%$ en población con $\mathrm{RM}$ de causa desconocida ${ }^{16}$. Este síndrome, previamente descrito en población chilena, se produce predominantemente por la expansión del triplete (CGG) en la región promotora del gen FMR1, ubicado en el brazo largo del cromosoma $\mathrm{X}^{17}$; clínicamente se manifiesta con un amplio espectro de disfunción del sistema nervioso central (SNC) que abarca desde dificultades de aprendizaje o problemas emocionales en sujetos con un CI limítrofe, hasta RM desde leve a profundo ${ }^{18}$. Otros factores que se relacionan con la variabilidad clínica, son los factores ambientales y educacionales que pueden potenciar o modificar el desarrollo, alterando el grado de disfunción resultante. Esta gran variabilidad fenotípica explica que 65\% de los casos de SXF sean subdiagnósticados, incluso en centros de genética especializados de países desarrollados ${ }^{19}$

Desde el punto de vista de la genética clínica, son evidentes los beneficios de determinar precozmente la etiología del $\mathrm{DI}^{20,21}$; sin embargo, aun para un número importante de profesionales del área de educación especial y manejo del comportamiento, la etiología del déficit intelectual es percibida como irrelevante, en la medida que ofrece escasa información práctica con respecto a las necesidades educativas de niños y adultos con $\mathrm{DI}^{22}$. Históricamente, la educación especial para 
déficit intelectual o retraso mental, ha puesto mayor énfasis en las consecuencias funcionales de la discapacidad que en el diagnóstico etiológico; privilegiando más la información psiquiátrica y otros diagnósticos del comportamiento al momento de definir los programas educativos ${ }^{5}$.

El objetivo del presente estudio fue determinar, a través de una "pesquisa genética para pacientes con déficit intelectual" (PGPDI) la frecuencia de afecciones genéticas y no genéticas como factor etiológico del DI, entre alumnos que asisten a escuelas de educación especial (EEE).

\section{Material y MÉTODOS}

I. Muestra. La muestra inicial consistió en 133 alumnos con déficit intelectual, no síndrome de Down, pertenecientes a dos EEE de Santiago, con edades comprendidas entre 5 y 24 años. La distribución correspondió a 83 alumnos de la Escuela Las Camelias de Champa, comuna de Paine y 50 de la Escuela Nuestro Mundo, comuna de San Ramón. A cada estudiante se le realizó una evaluación psico-educativa a través de las escalas de Weschler estandarizadas en Chile (WISC-R, WAIS), clasificándolos en los grados: leve, moderado y severo o profundo. Dichas evaluaciones fueron realizadas en cada establecimiento por un psicólogo acreditado ante el Ministerio de Educación; se evaluaron habilidades cognitivas de los alumnos, tales como atención, concentración, nivel de vocabulario, capacidad de análisis y síntesis, entre otras.

Siguiendo el protocolo establecido en la Figura 1, del total de la muestra considerada inicialmente ( $n$ =133), fueron incluidos en este estudio 103 alumnos. Treinta fueron excluidos por falta de firma del consentimiento informado, por retiro del alumno o por traslado a otra escuela durante el transcurso de la investigación. El protocolo de estudio y consentimiento informado fueron aprobados por el comité de ética del INTA.

Los 103 individuos estudiados (52 mujeres y 51 varones) con un promedio de edad de 13 años, fueron evaluados clínicamente en el policlínico de genética del INTA. Se utilizó una ficha especialmente diseñada (Figura 2) donde se consignaron antecedentes antropométricos, historia familiar en los casos en que fue posible y hallazgos del examen físico. En los pacientes con sospecha de síndrome alcohólico fetal (SAF) se utilizó el score propuesto por Hoyme ${ }^{23}$ y estudios chilenos previos $^{24,25}$. Las características clínicas generales de los pacientes se presentan en la Tabla 1 .

A 92 de los 103 sujetos se les tomó una muestra de sangre para realizar los análisis incluidos en la "pesquisa genética para pacientes con DI" (PGPDI) y los estudios genético-moleculares complementarios: test de metilación, FISH de microdeleciones y FISH subtelomérico, realizados sólo en los casos con diagnóstico clínico presuntivo.

En 11 de los 103 sujetos no se tomaron muestras de sangre ya que la evaluación clínica estableció un diagnóstico etiológico evidente que no justificó la realización del PGPDI.

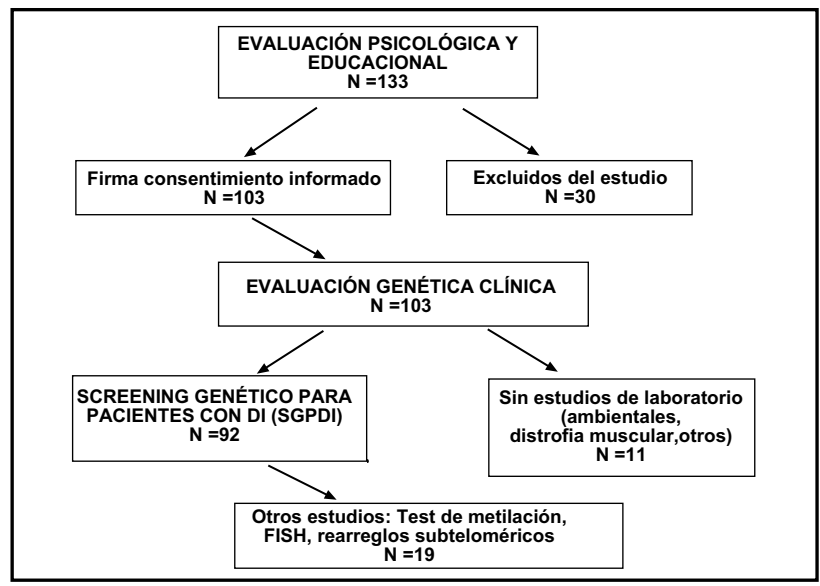

Figura 1. Protocolo de estudio y número de pacientes incluidos en las distintas evaluaciones. 


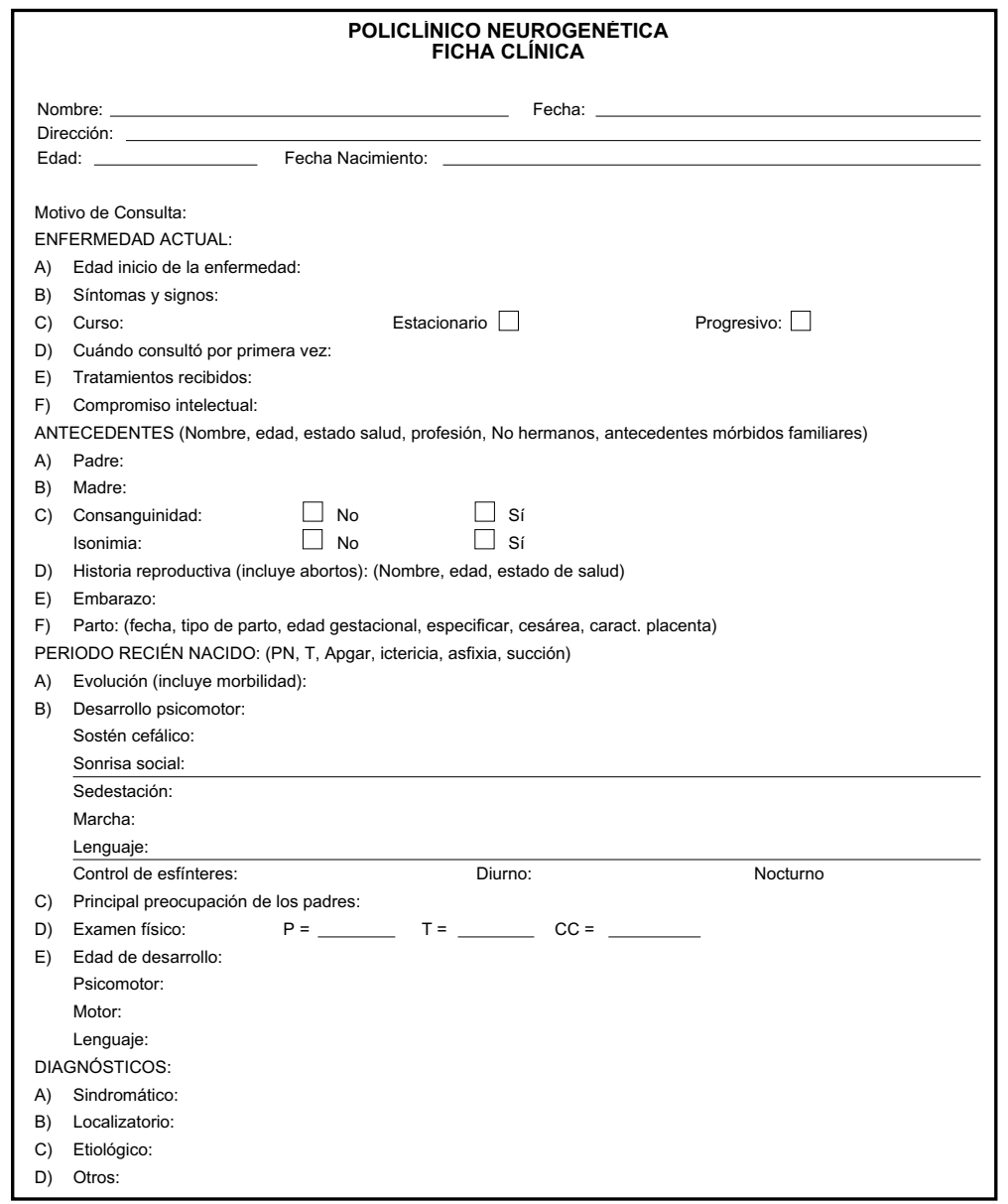

Figura 2.

\section{Tabla 1. C aracterísticas clínicas de 103 pacientes con D I}

\begin{tabular}{|lc|}
\hline Características & Total $\mathbf{N}=\mathbf{1 0 3}(\mathbf{\%})$ \\
\hline Género & \\
Hombres & 51 \\
Mujeres & 52 \\
Edad & \\
$\quad<10$ años & $13(12,6)$ \\
10 a 20 años & $86(83,4)$ \\
$>20$ años & $4(4)$ \\
Promedio & 13,2 años \\
Rango & 5 a 24 años \\
Nivel de DI & \\
Leve & $62(60)$ \\
Moderado & $30(29)$ \\
Severo & $11(11)$ \\
\hline
\end{tabular}

II. Pesquisa genética para pacientes con déficit intelectual (PGPDI). Incluyó los siguientes análisis:

1. Estudio citogenético: en cromosomas metafásicos obtenidos a partir de cultivos de linfocitos estimulados con fitohemaglutinina y analizados con bandeo GTG de alta resolución. La interpretación del cariotipo se realizó de acuerdo a lo establecido en la nomenclatura cromosómica internacional ${ }^{26}$.

2. Identificación de mutaciones en el gen FMR1: a partir de ADN genómico, utilizando los métodos de reacción de la polimerasa en cadena (PCR) y Southern blot, según el protocolo diseñado para este estudio (Figura 2).

a) Análisis por PCR. Se realizó sólo en los pacientes de sexo masculino ya que, por razones metodológicas propias del PCR se 


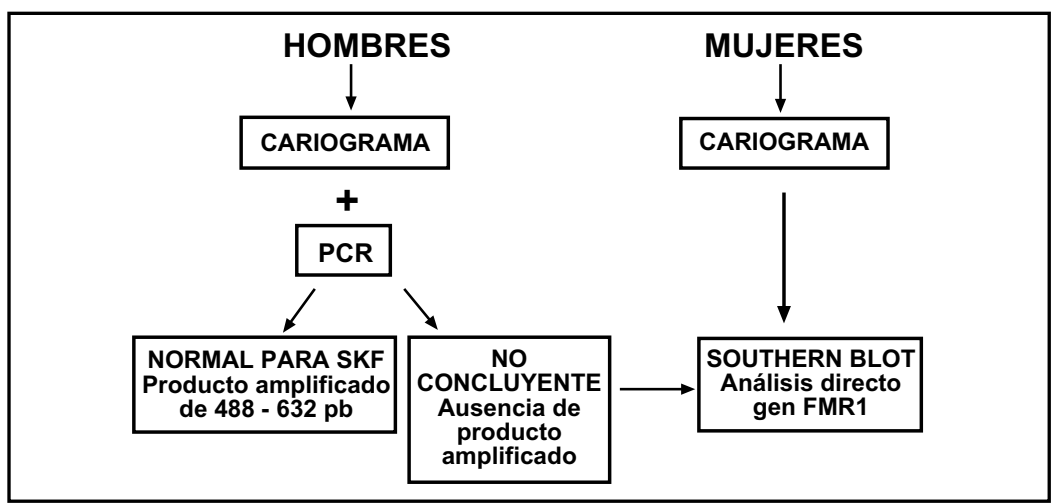

Figura 2. Protocolo propuesto para la pesquisa del síndrome Xq frágil (SXF) entre pacientes con déficit intelectual.

favorece la polimerizacón de repetidos CGG cortos; la presencia de otro cromosoma $\mathrm{X}$ normal produciría falsos negativos en las mujeres. El método descrito por Haddad y cols $1996^{27}$ utiliza partidores EagU y f y Eag L como control externo y visualizados con tinción de plata. En individuos normales se obtienen productos de PCR entre 488 y 632 pares de bases y 223 para el control externo.

b) Análisis directo del gen FMR1 por Southern blot. Se realizó en mujeres y en hombres con PCR alterado, según método descrito por Oberlé y cols en $1991^{28}$ y modificado en el laboratorio de citogenética molecular del INTA $^{29}$. Brevemente, se realizó doble digestión de $20 \mu \mathrm{g}$ de ADN con endonucleasas de restricción EcoR1 y EagI; luego de la electroforesis en gel de agarosa, el ADN se transfirió a una membrana de nylon Hybond $\mathrm{N}+$ (Amersham). La membrana se hibridó con la sonda StB 12.3 proporcionada por JL
Mandel (INSERM, Francia), marcada con quimioluminiscencia (CDP Star, Amersham) y visualizada por autorradiografía 30,31 .

3. Espectrometría de masa en tandem. Perfil de aminoácidos y acilcarnitina, a partir de una gota de sangre colocada en papel filtro (SIS 903), mediante el equipo Quattro Micro TM API (Micromass). El estudio permite descartar 30 errores innatos del metabolismo en un único ensayo.

\section{Resultados}

Evaluación psicológica. En la Figura 3 se presenta la distribución del DI según el grado de severidad en los 103 pacientes incluidos en el estudio.

Evaluación clínica y aplicación de PGPDI. Después de realizados los exámenes de laboratorio y reevaluada la información clínica, los pacientes fueron asignados a los siguientes grupos diagnósticos:

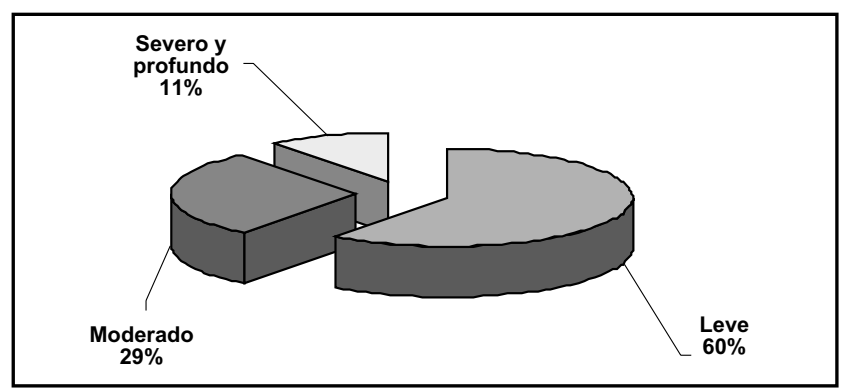

Figura 3. Frecuencia de la distribución de los 103 pacientes según grado de déficit intelectual (DI) de acuerdo a los valores del CI determinados en la evaluación psicológica. 
- Grupo I $(\mathrm{N}=14)$. En 9 casos (6 mujeres y 3 varones), se determinó un DI secuelar no genético, debido a causas ambientales, traumáticas o infecciosas; en los otros 5 casos (todas mujeres) se diagnosticó un síndrome alcohólico fetal (SAF).

- Grupo II $(\mathrm{N}=15)$. En 8 de los pacientes se estableció un diagnóstico clínico sin confirmación molecular; el cariotipo, gen FMR1 y estudio metabólico resultaron normales confirmando la condición clínica (Tabla 2). En los otros 7 casos se identificó una alteración citogenética o molecular, de ellos en 3 hombres se identificó el síndrome Xq frágil: dos con mutación completa y uno en mosaico (Figura 4 A y B); y en 4 casos se determinó una alteración cromosómica de tipo estructural con los siguientes cariotipos:

- 47,XX,+mar.ish i(18)(tel18p++,CEP+), paciente mujer con un cromosoma marcador extra. Con FISH subtelomérico se confirmó un isocromosoma 18p (Figura 5A).
- 46,XX,add(8)(p21), paciente mujer con un segmento adicional de origen desconocido en el brazo corto en un cromosoma 8 (Figura $5 \mathrm{C}$ y E).

- 46,X,der(X)(pter $\rightarrow$ q22::q23 $\rightarrow$ qter) paciente mujer con alteración del patrón de bandeo en el brazo largo de un cromosoma X (Figura 5B). El estudio de ambos padres resultó normal.

- 46,XY,t(3;9)(p21;q34)[2]/46,XY[33], paciente hombre con una translocación aparentemente balanceada entre los cromosomas 3 y 9 en mosaico.

- Grupo III ( $\mathrm{N}=74)$. En este grupo de pacientes con DI inespecífico, no fue posible establecer el diagnóstico etiológico. En 41 casos (55\%) el examen clínico determinó que las características fenotípicas e historia familiar eran compatibles con una afección genética; en 16/41 (39\%) se sospechó el síndrome Xq frágil, en los otros casos, la sospecha diagnóstica apuntaba a aberraciones cromosómicas, síndromes de mi-

Tabla 2. Resultados diagnósticos del screening genético para pacientes con D I (SG PD I)

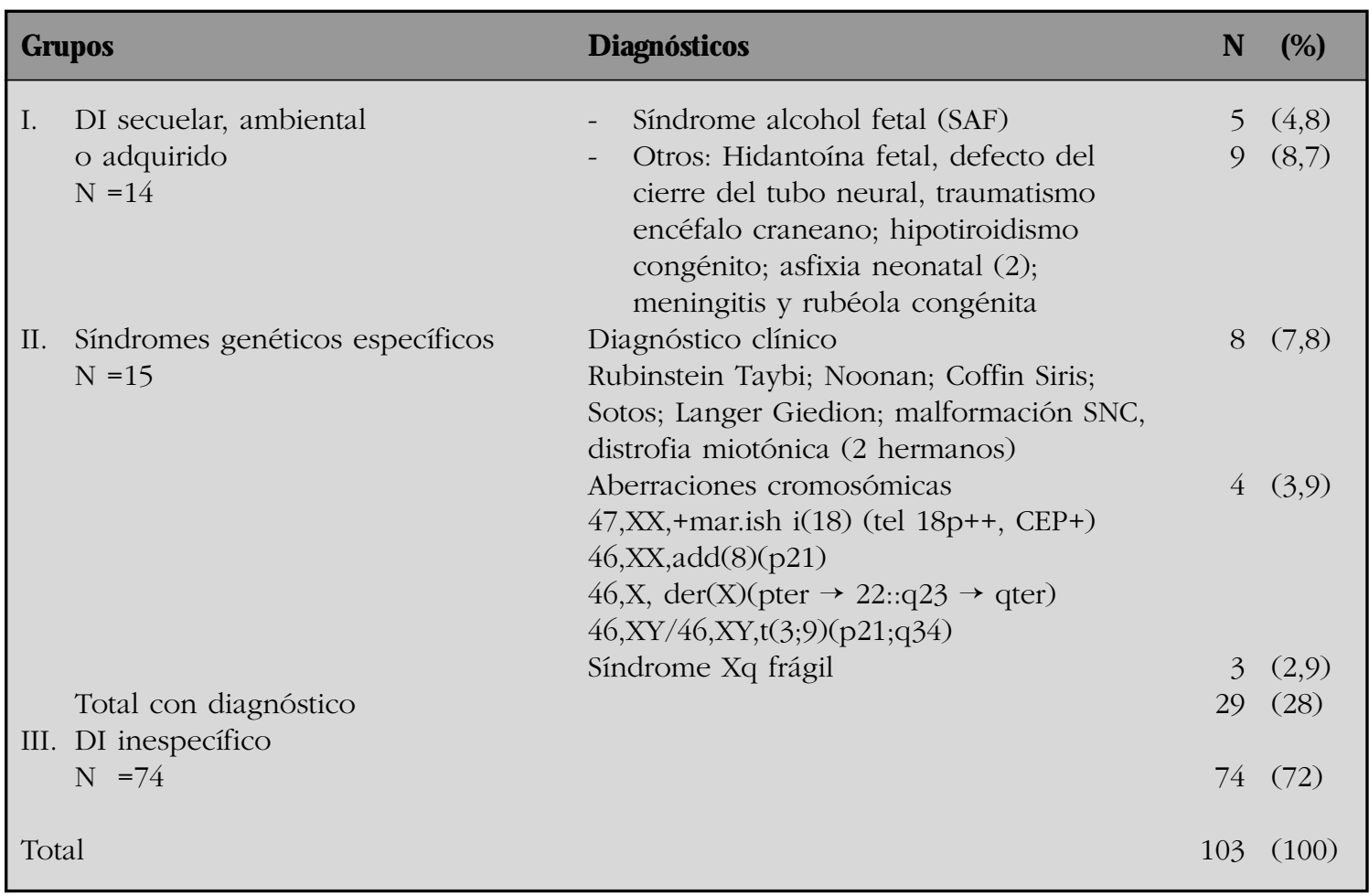




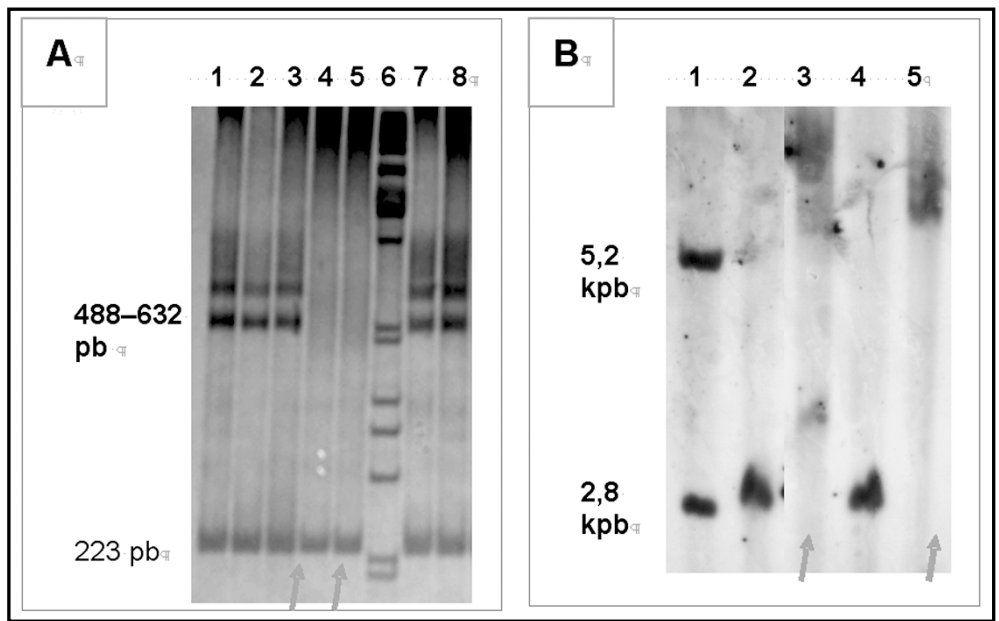

Figura 4. Identificación de mutaciones en el gen FMR1. A: PCR específico para síndrome Xq frágil en pacientes hombres. Las flechas muestran PCR alterado por ausencia de amplificado (entre 488 y 632 pb) en carriles 4 y 5 . B: Confirmación por Southern Blot y detección por quimioluminiscencia del tamaño y status de metilación del locus FRAXA en los pacientes hombres con PCR alterado y en mujeres. Carril 1: mujer normal; carriles 2 y 4 : hombres normales; carril 3: hombre mosaico premutación/mutación completa y carril 5: hombre con mutación completa.

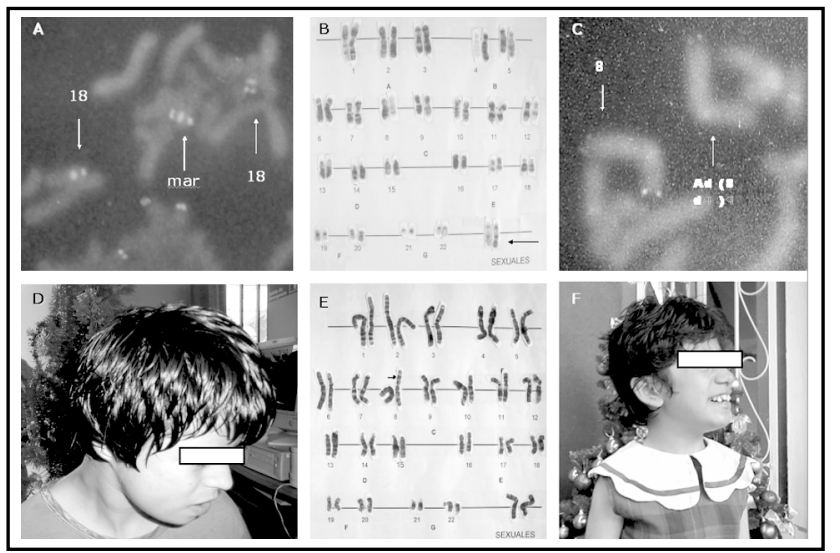

Figura 5. Resultados citogenéticos. A: Microfotografía parcial con FISH: 47,XX,+mar.ish i(18) (tel18p++, CEP+); las flechas marcan los cromosomas 18 normales y el isocromosoma 18p. B: Cariotipo: 46,X, der(X)(pter q22::q23 qter); la flecha marca el cromosoma X derivativo. C: Microfotografía parcial con FISH: 46,XX,add(8)(p21). D: Foto paciente con cariotipo 47,XX,+mar.ish der(18). E y F: Cariotipo y foto paciente con cariotipo 46,XX,add(8)(p21); la flecha marca el cromosoma 8 alterado.

crodeleción o rearreglos subteloméricos. En todos ellos los estudios genético-moleculares complementarios resultaron normales.

El estudio metabólico por espectrometría de masa resultó normal en los 92 pacientes estudiados.
En las Figuras 6 y 7 se presenta la distribución de los distintos diagnósticos según grado de DI. En los DI moderado a severo $(\mathrm{N}=41)$ se logró diagnóstico etiológico en 17 casos (41,6\%); sin embargo entre los pacientes del con DI leve $(\mathrm{N}=62)$ se diagnosticaron sólo 12 


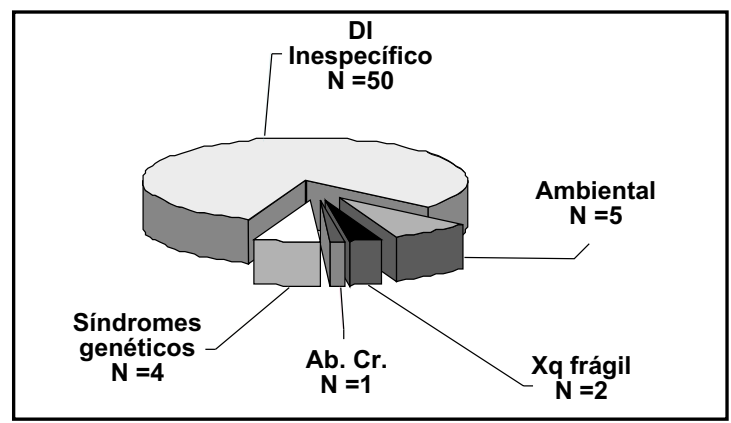

Figura 6. Distribución de diagnósticos etiológicos en 62 pacientes con DI leve. Ab.Cr. = aberraciones cromosómicas.

casos (19,3\%), esta diferencia es estadísticamente significativa $(\mathrm{p}>0,001)$.

En la Tabla 3 se muestra la distribución de los 103 pacientes en relación a los antecedentes familiares de DI; se observa que en el grupo con DI sin historia familiar se obtuvo el mayor porcentaje de casos diagnosticados $72,4 \%$ versus $27,5 \%$ en el grupo con historia familiar de DI. De los 39 casos con historia familiar de DI, en 35 de ellos ésta sería compatible con una herencia de tipo mendeliana.

\section{DISCUSIÓN}

Recientemente los campos de la genética médica y el déficit intelectual han encontrado puntos de convergencia importantes. La necesidad de estudio genético en el DI ha sido claramente establecida en una multiplicidad de trabajos de investigación, que buscan aportar datos al conocimiento de los fenotipos del comportamiento. De esta manera se pretende mejorar el manejo clínico de los pacientes

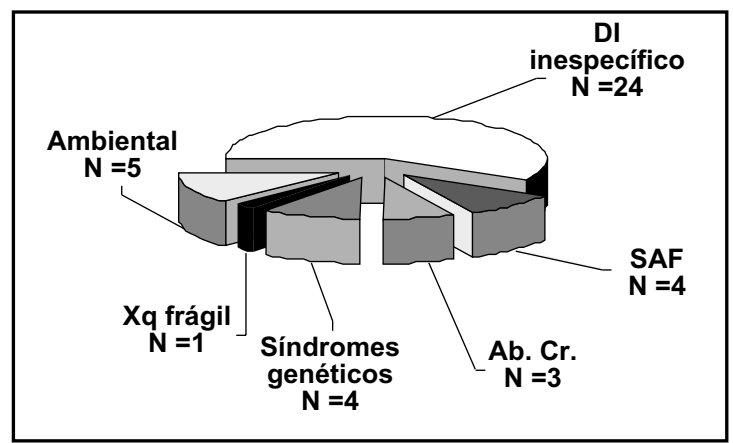

Figura 7. Distribución de diagnósticos etiológicos en 41 pacientes con DI moderado a severo. Ab.Cr. = aberraciones cromosómicas.

afectados, ayudar a sus familias y establecer mejores alternativas educativas.

La información surgida a partir de las investigaciones en genética, así como los aportes que hacen las agrupaciones de pacientes con síndromes específicos, ha provocado una mayor demanda por parte de los padres, de la comunidad en general y de los profesores de educación especial, por conocer el origen del déficit intelectual de los individuos afectados. Sin embargo y a pesar de que más de $80 \%$ de nuestros pacientes con DI superaban los 10 años de edad, sólo uno de ellos tenía diagnóstico etiológico al ingreso de este estudio.

$\mathrm{Al}$ respecto, es importante considerar que la literatura en general indica que estos estudios deben ser realizados lo más precozmente, idealmente antes de los 10 años ${ }^{6,7}$. Incluso algunos de los síndromes genéticos diagnosticados en este trabajo (Tabla 2), presentan evidencias clínicas desde la edad preescolar, por lo que estos resultados apoyan la necesidad de establecer una pesquisa temprana de enfermedades de etiología genética, en todo niño con DI que asista a una escuela especial.

\section{Tabla 3. Frecuencia de pacientes con y sin diagnóstico etiológico según antecedentes familiares de D I}

\begin{tabular}{|lccc|}
\hline Antecedentes & N (\%) & Con diagnóstico & Sin diagnóstico \\
\hline Con historia familiar de DI & $39(38)$ & $8(27,5)$ & $31(42)$ \\
A. Compatible con herencia Mendeliana & 35 & 8 & 27 \\
B. No compatible con herencia Mendeliana & 4 & 0 & 4 \\
Sin historia familiar de DI & $64(62)$ & $21(72,4)$ & $43(58)$ \\
Total & $103(100)$ & $29(28)$ & $74(72)$ \\
\hline
\end{tabular}


La implementación de la "pesquisa genética para pacientes con DI" (PGPDI) y el protocolo de estudio sugerido, demostraron ser una alternativa eficiente y de fácil aplicación para la pesquisa temprana de afecciones genéticas, especialmente en el grupo con DI moderado a severo y afecciones no genéticas como SAF y otras ambientales. El tipo de afecciones genéticas y no genéticas detectadas, tienen frecuencias similares a las descritas en la literatura9,10,24,25; sin embargo, al igual que en otros estudios, no fue posible identificar aberraciones cromosómicas crípticas y es necesario incorporar el "cariotipo molecular" para lograr identificar al menos dos veces más aberraciones cromosómicas que las detectadas con un cariotipo convencional ${ }^{11-13}$.

Con respecto al síndrome de Xq frágil, fue sospechado en 16 casos $(15,5 \%)$ y confirmado sólo en $3 \%$ de la muestra estudiada. Esta cifra es levemente inferior a la estimada en estudios previos en población chilena ${ }^{17,18}$; sin embargo, al igual que otros estudios, representa la principal sospecha clínica y la alteración única más frecuente entre pacientes con DI no síndrome de Down, que asisten a $\mathrm{EEE}^{7,8,20,22}$. Por esto se planteó un protocolo de estudio de Xq frágil (Figura 4) que incluye el diagnóstico de las mutaciones en el gen FMR1, utilizando el método de PCR en hombres. Esta metodología aumenta la eficiencia y posibilita el diagnóstico precoz en un mayor número de casos; de esta manera es posible entender el amplio espectro de manifestaciones de este trastorno y vislumbrar otros problemas más sutiles que el DI, como la ansiedad y las dificultades de aprendizaje en estos pacientes ${ }^{19}$.

El estudio metabólico realizado a través de espectrometría de masa en tandem, no mostró alteraciones en ninguno de los pacientes estudiados, por lo que no se justificaría su uso como metodología de tamizaje, en el estudio etiológico del retraso mental; esto es concordante con la literatura que muestra que sólo en 1\% de los individuos mayores de 5 años con retraso mental

\section{REFERENCIAS}

1. The American Association on Mental Retardation. What is Mental Retardation? Disponible en: http:// www.aamr.org/Policies/pdf/definitionofMR.pdf (consultado el 30.06.2008)

2. Curry CJ, Stevenson Re, Aughton D, Byrne J, Carey JC, leve-moderado se ha detectado una alteración metabólica como causa etiológica ${ }^{6}$.

En relación a la existencia o no de una historia familiar de DI, en el grupo sin DI familiar $(\mathrm{N}=64)$ se logró un diagnóstico etiológico en 21 casos (33\%); a diferencia del grupo con historia de DI en la familia $(\mathrm{N}=39)$ en que se diagnosticaron 8 casos (20,5\%). Esta situación se explica porque las alteraciones diagnosticadas en el primer grupo corresponden principalmente al tipo esporádico, con bajo riesgo de recurrencia; en el segundo grupo, al igual que lo informado en otros estudios, podrían haber alteraciones cromosómicas crípticas o mutaciones ligadas al cromosoma $\mathrm{X}$, que no pudieron ser detectadas con los métodos aquí utilizados ${ }^{32}$.

Se determinó una diferencia estadísticamente significativa entre el número de casos diagnosticados con una afección genética, en el grupo de niños con DI moderado y severo, comparado con el grupo de DI leve (41,5\% versus 19,4\% p >0,001) (Figuras 6 y 7). Experiencias previas muestran datos similares en el sentido de que las afecciones genéticas producen un grado mayor de compromiso del $\mathrm{DI}^{33}$; a partir de estos datos es posible apoyar la idea de que el PGPDI propuesto en este estudio es especialmente eficiente en el grupo de DI moderado a severo.

El presente estudio permitió detectar un número importante de afecciones genéticas, responsables del déficit intelectual de alumnos que asisten a escuelas de educación especial de la Región Metropolitana; demostrando que dichas afecciones genéticas juegan un rol etiológico importante en el DI y que el reconocerlas precozmente favorecería el mejor desempeño educativo y social de estos pacientes, a través de intervenciones educativas especificas.

\section{Agradecimientos}

Los autores agradecen a la Dra. Andrea Pardo por haber realizado el examen clínico de algunos pacientes y por su aporte crítico a la realización de este trabajo.

CASSIDY S ET AL. Evaluation of mental retardation: Recommendations of a Consensus Conference: American College of Medical Genetics. Am J Med Genet 1997; 72: 468-77.

3. Battaglia A, Bianchini E, Carey JC. Diagnostic yield of the comprehensive assessment of developmental delay/mental retardation in an institute of child neuropsychiatry. Am J Med Genet 1999; 82: 60-6. 
4. Moser HW. Genetic causes of mental retardation. Ann NY Acad Sci 2004; 1038: 44-8.

5. Kenner C, Gallo AM, Bryant KD. Promoting children's health through understanding of genetics and genomics. J Nursing Scholarship 2005; 37: 30814.

6. Poplawski NK. Investigating intellectual disability: A genetic perspective. J Paediatr Child Health 2003; 39: 492-506

7. Rauch A, Hoyer J, Guth S, Zweier C, Kraus C, Becker C. Diagnostic yield of various genetic approaches in patients with unexplained developmental delay or mental retardation. Am J Med Genet 2006; 140: 2063-74.

8. De Vries BB, Pfundt R, Leisink M, Koolen DA, Vissers LE, JANSSEN IM. Diagnostic genome profiling in mental retardation. Am J Hum Genet 2005; 77: 60616.

9. Hayflick SJ, Eiff MP, Carpenter T, Steinberger J. Primary care physicians utilization and perceptions of genetics services. Genet Med 1998; 1: 13-21.

10. Xu J, Chen Z. Advances of molecular cytogenetics for the evaluation of mental retardation. Am J Med Genet 2003; 117C: 15-24.

11. Funt J, Knight S. The use of telomere probes to investigate submicroscopic rearrangements associated with mental retardation. Curr Opin Genet Dev 2003; 13: 310-16.

12. Rauch A, Rüschendorf F, Huang J, Trautmann U, BeCKer C, Thiel C et AL. Molecular karyotyping using an SNP array for genomewide genotyping. J Med Genet 2004; 41: 916-22.

13. Rosenberg C, Knijnenburg J, Bakker E, Vianna-Morgante AM, Sloos W, Otto PA et al. Array-CGH detection of micro rearrangements in mentally retarded individuals: clinical significance of imbalances present both in affected children and normal parents. J Med Genet 2006; 43: 180-6.

14. Turner G, Webb T, Wakes S, Robinson S. Prevalence of fragile X syndrome. Am J Med Genet 1996; 64: 196-7.

15. Morton J, Bundey S, Webb T, Macdonald F, Rindl PM, Bullock S. Fragile X syndrome is less common than previously estimated. J Med Genet 1997; 34: 1-5.

16. Murray J, Cuckle H, Taylor G, Hewison J. Screening for fragile X syndrome: information needs for health planners. J Med Screening 1997; 4: 60-94.

17. Jara L, López M, Mellado C, Aspillaga M, Avendaño I, Blanco R. Clinical and molecular screening for fragile X syndrome in 300 patients with non-specific mental retardation. Rev Méd Chile 1998; 126: 911-8.

18. Aspillaga M, Jara L, Avendaño I, López M. Fragile X syndrome. Clinical analysis of 300 Chilean patients with unspecific mental retardation. Rev Méd Chile 1998; 126: 1447-54.
19. Hagerman RJ, Hagerman PJ. El síndrome X frágil: un modelo de la relación gen- cerebro- conducta. Rev Neurol 2001; 33: S51-S57.

20. LEwIS MES. Genes, screens and means for advancing the diagnosis and anticipatory care of individuals with congenital intellectual disability. Clin Genet 2004; 65: 1-6.

21. Van Naarden Braun K, Autry A, Boyle C. A population-based study of the recurrence of developmental disabilities - Metropolitan Atlanta Developmental Disabilities Surveillance Program, 1991-94. Paed Perinatal Epid 2005; 19: 69-79.

22. Finucane B, Haas-Givler B, Simon EW. Genetics, mental retardation, and the forging of new alliances. Am J Med Genet 2003; 117: 66-72.

23. Hoyme he, May PA, Kalberg WO, Kodituwakku P, Gossage JP, Trujillo PM et al. A practical clinical approach to diagnosis of fetal alcohol spectrum disorders: clarification of the 1996 institute of medicine criteria. Pediatrics 2005; 115: 39-47.

24. Alvear J, Andreani S, Cortés F. Fetal alcohol syndrome and fetal alcohol effects: importance of early diagnosis and nutritional treatment. Rev Méd Chile 1998; 126: 407-12.

25. Mena M, Navarrete P, Avila P, Bedregal P Berríos X. Alcohol drinking in parents and its relation with intelectual score of their children. Rev Méd Chile 1993; 121: 98-105.

26. ISCN. An International System for Human Cytogenetic Nomenclature. Shaffer LG and Tommerup N (eds) S. 2005. Karger, Basel.

27. Haddad La, Mingroni-Netto RC, Vianna-Morgante AM, Pena SD. A PCR-based test suitable for screening for fragile $\mathrm{X}$ syndrome among mentally retarded males. Hum Genet 1996; 97: 808-12.

28. Oberlé I, Rosseau F, Heitz D, Kretz C, Devys D, Hanauer A ET AL. Instability of a 550-base pair DNA segment and abnormal methylation in fragile $\mathrm{X}$ syndrome. Science 1991; 252: 1097-102.

29. Alliende MA, Curotto B, Valiente A, Toro J, González M. Diagnóstico citogenético-molecular del síndrome Xq frágil. Rev Tec Med 2007; 27: 339-46.

30. Rousseau F, Heitz D, Biancalana V, Oberlé I, Mandel JL. On some technical aspects of direct DNA diagnosis of the fragile X syndrome. Am J Med Genet 1992; 43: 197-207.

31. Schaffer H, Sederoff R. Least squares fit of DNA fragment length to gel mobility. Anal Biochem 1981; 115: 113-22.

32. Ropers HH. X-linked mental retardation: many genes for a complex disorder. Curr Opinion in Genet Develop 2006; 16: 260-9.

33. Ropers HH, Hamel BC. X-linked mental retardation. Nat Rev Genet 2005; 6: 46-57. 